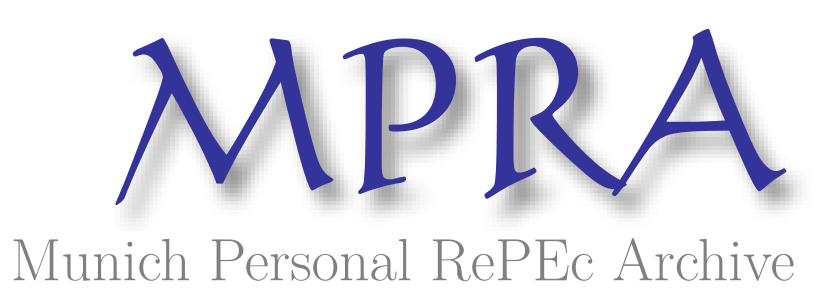

\title{
CO2 Emissions, Research and Technology Transfer in China
}

\author{
Ang, James \\ Monash University
}

9 February 2009

Online at https://mpra.ub.uni-muenchen.de/13261/

MPRA Paper No. 13261, posted 12 Feb 2009 05:09 UTC 


\title{
CO2 EMISSIONS, RESEARCH AND TECHNOLOGY Transfer in China
}

\begin{abstract}
Although the economy of China has grown very strongly over the last few decades, this spectacular performance has come at the expense of rapid environmental deterioration. Amidst animated debate on the issue of global warming, this study attempts to explore the determinants of $\mathrm{CO}_{2}$ emissions in China using aggregate data for more than half a century. Adopting an analytical framework that combines the environmental literature with modern endogenous growth theories, the results indicate that $\mathrm{CO}_{2}$ emissions in China are negatively related to research intensity, technology transfer and the absorptive capacity of the economy to assimilate foreign technology. Our findings also indicate that more energy use, higher income and greater trade openness tend to cause more $\mathrm{CO}_{2}$ emissions.
\end{abstract}

Keywords: Environmental pollution; endogenous growth theory; R\&D, China. JEL classification: O30; O40; O53; Q40, Q50 


\section{Introduction}

The debate over global climate change has attracted copious attention from academic researchers and policy makers in recent years. As the major new global player, China's spectacular economic growth has been widely observed over the past few decades. Since the economic reforms of 1978, China has recorded an average real growth rate exceeding nine percent a year. Per capita real income has increased almost tenfold during this period. Alongside this strong growth performance, there has been an associated rapid rise in energy consumption and pollution emissions. Energy use in China grew at an annual average rate of 7.2 percent during the period 1953-2006. Annual pollution emissions, measured by $\mathrm{CO}_{2}$ in metric tons of carbon, increased from just 36.6 million in 1953 to 1625.7 million in 2006, representing a more than forty-fold increase.

In a recent study, Auffhammer and Carson (2008) highlight that the slowing of China's $\mathrm{CO}_{2}$ per capita emissions growth rates, as previously predicted, is unlikely to materialize in the near future. In contrast, their forecasts suggest that China's $\mathrm{CO}_{2}$ emissions are likely to increase dramatically over the short to medium term, and significantly exceed the amount required in the Kyoto Protocol. With rapid growth in pollution emissions, there has been increasing concern about their impact on China and the global economy. According to a recent study by Nielsen and Ho (2007), the aggregate national environmental health damage is estimated to be in the range of 3 percent to 7.7 percent of GDP. Moreover, The World Bank (2007) reports that the environmental pollution cost in China is estimated to be about 5.8 percent of its GDP.

While the importance of global warming issues is widely recognized among economists and policy makers, there has so far been little effort attempting to examine environmental performance in China, despite it currently being responsible for about one-fifth of global emissions. Most previous studies on this subject have focused on examining the future trends of energy consumption or $\mathrm{CO}_{2}$ emissions in China (see, e.g., Chan and Lee, 1996; Sinton and Fridley, 2000; Crompton and Wu, 2005; Auffhammer and Carson, 2008). An important exception to this is the study by Cole et al. (2008), who focus on examining the determinants of environmental pollution for China using industry-level data for the period 1997-2003. Their results show that energy use and human capital have a positive impact on industrial pollution whereas productivity improvements and research activity tend to reduce emissions.

Our study differs from Cole et al. (2008) in several aspects. First, we utilize time series data for China going back as far as 1950. The use of a sufficiently long dataset enables us to analyze the long-run determinants of pollution as well as the short-run dynamics. Second, to the best of our knowledge, this is the first attempt that satisfactorily combines the environmental 
literature with modern endogenous growth theories. By doing so, it allows us to focus on the roles of $\mathrm{R} \& \mathrm{D}$ activity and technology transfer in reducing $\mathrm{CO}_{2}$ emissions. This is done by incorporating factors that could induce higher productivity growth, as suggested by modern growth literature, into the pollution function. The rest of the paper is organized as follows. Section 2 sets out the analytical framework. Section 3 discusses construction of variables, data sources and the estimation techniques. Section 4 performs the empirical analysis and presents the results. The last section summarizes the results and concludes.

\section{Theoretical Framework}

This section sets out the analytical framework underlying our empirical modeling strategy. Assuming a standard neoclassical production function with constant returns, we can write the aggregate output $\left(y_{t}\right)$ function at time $t$ as:

$$
y_{t}=A_{t} f\left(K_{t}, L_{t}\right)
$$

where $A_{t}$ is total factor productivity (TFP), $K_{t}$ is the capital stock and $L_{t}$ is the number of workers. Bernard and Jones (1996a, b) assume that TFP growth $\left(g_{A}\right)$ depends on technological catch-up so that:

$$
g_{A}=\frac{\dot{A}_{t}}{A_{t}}=f\left(D T F_{t-1}\right)
$$

where $D T F_{t}$ is a variable measuring the technology gap between the frontier and the domestic economy (or distance to the frontier). The underlying principle in this simple model is that countries which are relatively backward can grow faster by utilizing technologies developed in the leading country. Therefore, a positive effect of $D T F_{t}$ is expected due to the role of technology transfer in productivity growth. However, the above formulation of productivity catch-up is inadequate to explain the complex evolution of the growth rate in TFP. In this connection, we modify the above simple TFP growth specification in the following ways.

First, there is now an extensive literature on endogenous growth that emphasizes the importance of R\&D efforts as an engine of growth. The key argument of the research-induced growth models is that TFP growth moves closely with R\&D activity. For instance, the models of 
Romer (1990), Segerstrom et al. (1990), Grossman and Helpman (1991b) and Aghion and Howitt (1992)) suggest that the rate of productivity growth $\left(g_{A}\right)$ depends on the growth rate of the R\&D stock of knowledge:

$$
g_{A}=\frac{\dot{A_{t}}}{A_{t}}=\rho \frac{\dot{S K_{t}}}{S K_{t}}
$$

where $S K_{t}$ is the stock of R\&D knowledge. For low rates of depreciation of R\&D stock, we can write the above as:

$$
\dot{A}_{t}=v A_{t}\left(\frac{X}{Q}\right)_{t}
$$

where $X_{t}$ is $\mathrm{R} \& \mathrm{D}$ input and $Q_{t}$ represents the variety of products in the economy. The ratio $(X / Q)_{t}$ is commonly referred to as research intensity. The above framework is in line with the Schumpeterian version of the R\&D-based growth models of Aghion and Howitt (1998), Dinopoulos and Thompson (1998), Peretto (1998) and Howitt (1999). These models suggest the effectiveness of $R \& D$ is diluted due to the proliferation of products when an economy expands so that we can assume constant returns to the stock of R\&D knowledge.

Second, there is a growing literature suggesting that domestic research activity plays a crucial role in facilitating the transfer of foreign technology (see Howitt, 2000; Griffith et al. 2003, 2004; Cameron et al., 2005; Hu et al., 2005). For instance, using a general equilibrium model of endogenous growth, Griffith et al. (2003) combine the above two strands of literature and show that $R \& D$, in addition to its direct effect, has an indirect effect on productivity growth that operates through the speed of technological catch-up. Specifically, a lagged interaction term between $D T F_{t}$ and $(X / Q)_{t}$ is introduced to capture the second facet of R\&D activity. It is postulated that the effect of R\&D efforts on TFP growth will be greater for countries that lie further behind the technological frontier. As such, this interaction term, also known as the absorptive capacity, is expected to have a positive influence on TFP growth.

Third, recent studies have found that greater openness in the trade sector is positively associated with higher productivity growth-enhancing effects (see, e.g., Coe et al., 1997; Ades and Glaeser, 1999; Alesina et al., 2000; Choudhri and Hakura, 2000). In the models developed 
by Grossman and Helpman (1990, 1991a), trade openness affects firms' decisions to develop new products, which in turn depend on international competition and market size. Thus, international trade can promote more innovative activities in the domestic market and lead to higher productivity.

An augmented equation for TFP growth that incorporates these considerations can be given as follows:

$$
g_{A}=\frac{\dot{A}_{t}}{A_{t}}=f\left[(X / Q)_{t-1}, D T F_{t-1},(X / Q)_{t-1} \mathrm{x} D T F_{t-1}, T O_{t}\right]
$$

The literature suggests that per capita energy use $\left(E_{t}\right)$ and per capita real output $\left(Y_{t}\right)$ are the key determinants of pollutant emissions (see, e.g., Liu, 2005; Ang, 2007). However, an unproductive economy can also generate more pollution. This is because a country which is more productive is able to use resources more efficiently (see Cole et al., 2005, 2008). In principle, higher productivity growth induced by technology transfer and more R\&D efforts can improve environmental performance. This would be the case when a large proportion of the imported technology focuses on pollution abatement and R\&D activities relate to the creation of clean technology that better protects the environment. Therefore, a more complete characterization of the pollution function should include productivity growth as a key determinant. Incorporating the role of TFP growth in abating pollution, we can write the environmental pollution function as: ${ }^{1}$

$$
C_{t}=h\left[E_{t}, Y_{t}, f\left(g_{A}\right)\right]
$$

Using the above TFP growth specification in Eq. (5), we can write the pollution equation as:

\footnotetext{
1 We have also attempted to model the pollution function using the environmental Kuznets curve (EKC) framework. The results are, however, less satisfactory. This is not surprising given that an EKC specification may not be appropriate for a developing country like China. In fact, previous studies by Ang $(2007,2008)$ have shown that such a specification is appropriate for France but not Malaysia. Moreover, Auffhammer and Carson (2008) show that an EKC specification for China yields sub-optimal forecast results. See also Wagner (2008) who show that the inverted U-shaped relationship found in the literature appears to be spurious and disappears once the observations have been appropriately de-factored.
} 


$$
\begin{aligned}
\ln C_{t}= & \alpha+\beta_{1} \ln E_{t}+\beta_{2} \ln Y_{t}+\beta_{3} \ln T O_{t}+\beta_{4} \ln (X / Q)_{t-1}+\beta_{5} \ln D T F_{t-1} \\
& +\beta_{6}[\ln (X / Q) \mathrm{x} \ln D T F]_{t-1}+\beta_{7} \operatorname{Reg}+\varepsilon_{t}
\end{aligned}
$$

where $C_{t}$ refers to an indicator of environmental quality for China (proxied by per capita $\mathrm{CO}_{2}$ emissions), $\beta^{\prime} s$ represent the long-run elasticities and $\varepsilon_{t}$ is Gaussian errors. $\beta_{1}$ and $\beta_{2}$ are expected to be positive according to the literature. Greater trade openness is likely to result in more competition, causing the least productive and least energy-efficient firms to leave the market. However, Antweiler et al. (2001) and Cole and Elliott (2003), among others, postulate that the environmental impact of trade liberalization can be decomposed into scale (size of economy), technique (production methods) and composition (specialization) effects. While more pollution may occur due to the scale effect, the technique effect is likely to be beneficial to the environment. The composition effect depends on the country's comparative advantage. Hence, the net effect of free trade on the environment depends on the relative strength of each opposing force, and is therefore ultimately an empirical issue. Thus, the expected sign for $\beta_{3}$ is indeterminate. The expected signs for $\beta_{4}, \beta_{5}$ and $\beta_{6}$ are negative since $\mathrm{R} \& \mathrm{D}$ activity, technology gap and the absorptive capacity of technology transfer are expected to reduce pollution. Finally, following Cole et al. (2008), the empirical specification of the pollution function presented above also considers a legal dummy variable $(\operatorname{Reg})$, which captures the effect of adoption of the Environmental Protection Law since 1979. Eq. (7) will be estimated using annual data for China over the period 1953-2006.

\section{Data and Estimation Techniques}

\subsection{Measurement and data sources}

This section describes the construction of variables, data sources and econometric techniques employed in the analysis. Long historical data on pollution for China are not available from any domestic official source. Therefore, we have obtained the data from an international source compiled by the Carbon Dioxide Information Analysis Center. ${ }^{2}$ Following most prior studies (see, e.g., Holtz-Eakin and Selden, 1995; Friedl and Getzner, 2003; MartinezZarzoso and Bengochea-Morancho, 2004; Liu, 2005; Ang, 2007, 2008; Auffhammer and Carson, 2008), we consider per capita $\mathrm{CO}_{2}$ emissions $\left(C_{t}\right)$ as the measure for the level of pollution. It refers to the total emissions from fossil-fuel burning, cement manufacture and gas flaring. Data for other types of emissions going back as far as the 1950s are unfortunately not

\footnotetext{
${ }^{2}$ The data are available for download at: http://cdiac.ornl.gov/ftp/trends/emissions/prc.dat.
} 
available. Real GDP and energy consumption data are directly obtained from the China Statistical Yearbook. In line with $\mathrm{CO}_{2}$ emissions, these two series are divided by population. We use the standard trade intensity measure, i.e., the sum of exports and imports over GDP, as the proxy for trade openness $\left(T O_{t}\right)$.

In the literature, it is common to use either $R \& D$ labor or real $R \& D$ expenditure as the proxy for R\&D input $\left(X_{t}\right)$. However, data for R\&D personnel are only available from 1978 . The lack of R\&D personnel data for the entire estimation period prompts us to consider using only $R \& D$ expenditure in the analysis. $R \& D$ expenditure, which is available continuously from 1953 , is proxied by total scientific research expenditure. This is obtained from the National Bureau of Statistics of China (1999), and more recent data are taken from the China Statistical Yearbook. Largely due to the lack of R\&D data for developing countries, almost all previous work on R\&D-based growth models has focused only on OECD countries (see, e.g., Zachariadis, 2003; Guellec and De la Potterie, 2004; Ha and Howitt, 2007).

Distance to the frontier can be measured as follows:

$$
D T F_{t}=\frac{A_{t}^{L}-A_{t}}{A_{t}^{L}}
$$

where $A_{t}^{L}$ is the level of total factor productivity of the technological leader at time $t$. Following the general practice in the literature, we take the United States as the technological frontier (see, e.g., Cameron et al., 2005; Madsen et al., 2008). The further China lies behind the technological leader, the larger the technology gap and therefore the greater the potential for technology transfer to benefit productivity growth and thereby reduce pollution.

Total factor productivity is computed as $Y_{t} / K_{t}^{\pi} L_{t}^{1-\pi}$. We use gross domestic product at constant price as the measure of real output $\left(Y_{t}\right)$. Real capital stock $\left(K_{t}\right)$ is computed using the perpetual inventory method (i.e., $\left.K_{t}=I_{t}+(1-\delta) K_{t-1}\right)$. In line with Coe and Helpman (1995), a depreciation rate $(\delta)$ of $5 \%$ and the growth rate of gross capital formation $(g)$ at constant prices during the sample period, 1953-2006, are used to obtain the initial stock $\left(K_{0}\right)$ for the year 1953 , so that $K_{0}=I_{0} /(g+\delta)$, where $I_{0}$ is real gross capital formation in 1953. Following the established practice in the literature, capital's share of income $(\pi)$ is set at 0.3 . National account statistics for the U.S. are collected from the Bureau of Economic Analysis whereas labor data are taken from the Bureau of Labor Statistics. Data for $Y_{t}, K_{t}$ and $L_{t}$ for China covering the 
period 1953-1999 are obtained from Wang and Yao (2003). We extend the data using more recent data points available from the China Statistical Yearbook.

Figure 1: Time series plots of variables (1953-2006)
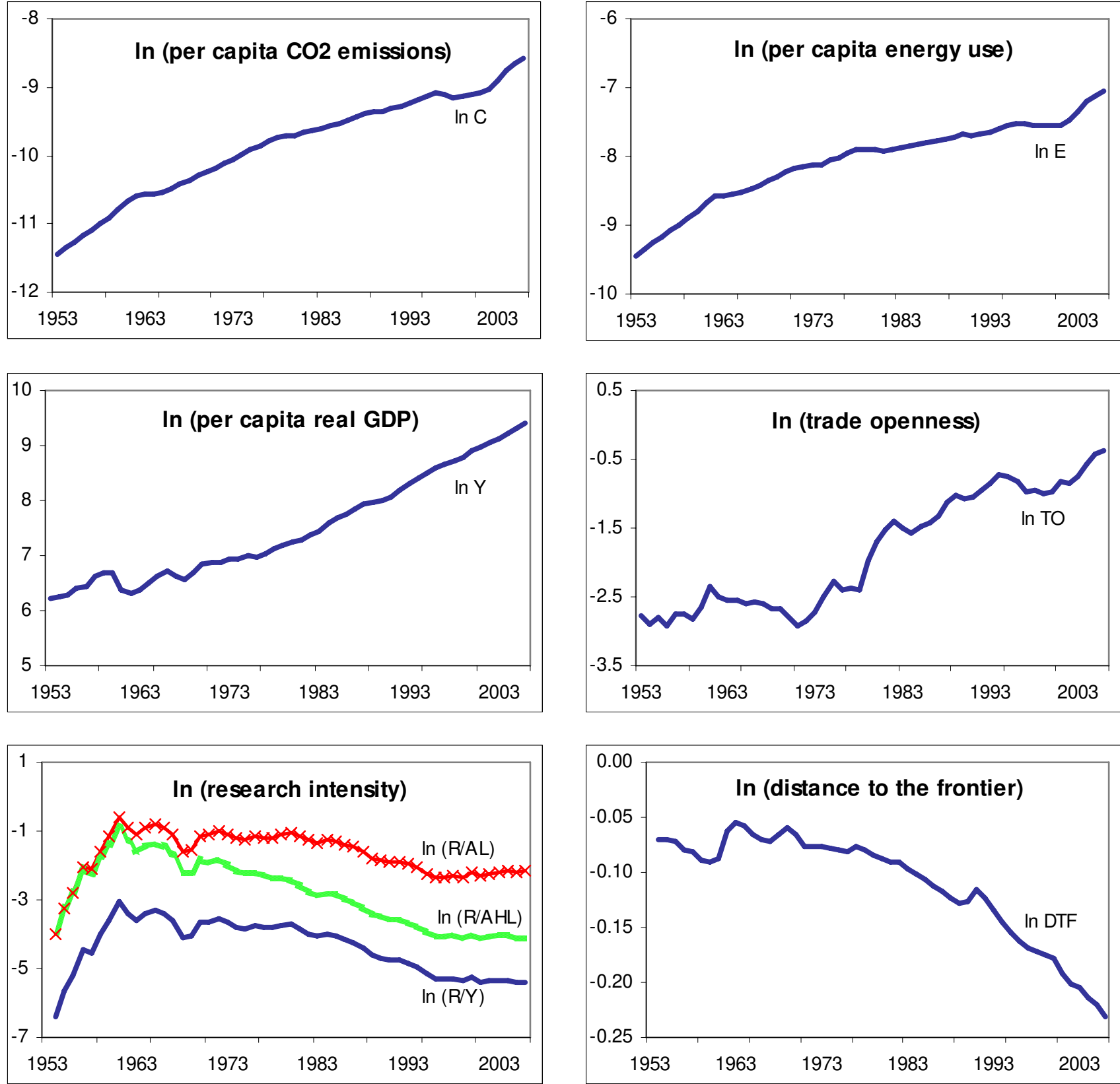

To measure $R \& D$ expenditure in real terms, we deflate by an unweighted average of a wage index and the GDP deflator. The former is constructed using data for average earnings of workers in urban units available from the China Statistical Yearbook. Data before 1978 are backdated by assuming that the growth rate of wages can be approximated by the sum of the rate of inflation and the growth rate in labor productivity $\left(Y_{t} / L_{t}\right)$. Product variety $\left(Q_{t}\right)$ is measured 
by number of workers $\left(L_{t}\right)$ and real output $\left(Y_{t}\right)$. However, some adjustments for the measure of product variety are necessary given that there is a tendency for decreasing returns to $R \& D$ due to the increasing complexity of innovation (Ha and Howitt, 2007). Thus, labor is adjusted for productivity and human capital so that the following two additional measures of research intensity are also considered: $R_{t} / A_{t} L_{t}$ and $R_{t} / A_{t} H_{t} L_{t}$, where $A_{t}$ is total factor productivity, and $H_{t}$ is the stock of human capital, which is proxied by the average years of schooling. These additional measures therefore account for productivity or human capital adjustments or both. Data on human capital stock are obtained from Wang and Yao (2003) and extended accordingly using the methodology therein. ${ }^{3}$

The time series plots of the variables used in the empirical analysis are presented in Figure 1. It is evident that per capita $\mathrm{CO}_{2}$ emissions $\left(C_{t}\right)$, per capita energy use $\left(E_{t}\right)$, per capita real output $\left(Y_{t}\right)$ and trade openness $\left(T O_{t}\right)$ all show a strong increasing trend over time. The measures of research intensity $\left(R_{t} / Y_{t}, R_{t} / A_{t} L_{t}\right.$ and $\left.R_{t} / A_{t} H_{t} L_{t}\right)$ increase sharply during the 1950s and peak in the early 1960s. Since then, the series have been associated with a mild decreasing trend. The decline in the measure for distance to the frontier $\left(D T F_{t}\right)$ indicates that the Chinese economy is catching up with the world technological leader.

\subsection{Econometric Techniques}

We adopt the traditional ARDL approach to the estimation of the long-run relationship and the short-run dynamics for environmental pollution and its determinants. Pesaran and Shin (1999) have shown that the OLS estimators of the short-run parameters are consistent, and the ARDL based estimators of the long-run coefficients are super-consistent in small sample sizes. Hence, valid inferences on the long-run parameters can be made using standard normal asymptotic theory. Moreover, this estimator is applicable irrespective of whether the regressors are $I(0)$ or $I(1)$. The optimal orders of the ARDL model are selected using the SIC by allowing for one lag in the estimation. In order to test the robustness of the results, all estimations are subject to various diagnostic tests. To provide for robustness checks, the environmental pollution equation is also estimated using three alternative single-equation estimators, namely the fully-modified OLS (FM-OLS) estimator of Phillips and Hansen (1990), the fully-modified unrestricted error-correction model (FM-UECM) of Inder (1993) and the dynamic ordinary least squares (DOLS) technique of Stock and Watson (1993).

\footnotetext{
${ }^{3}$ These data are also available from Rawski and Perkins (2008).
} 
Using the Wald tests, the resulting test statistics from the FM-OLS procedure are "fullymodified" by semiparametric corrections for serial correlation and for endogeneity. This "fully modified" procedure has been found to work well in finite samples, a feature which is particularly appealing given the small sample size used in the present study. In implementing the FM-UECM procedure, we follow Bewley (1979) by using the instrumental variable technique to correct the standard errors so that valid inferences can be drawn. Inder (1993) suggests that lagged level variables can be used as the instruments for the first-different current terms to correct for endogeneity bias. The key advantage of the DOLS procedure is that it allows for the presence of a mix of $I(0)$ and $I(1)$ variables in the cointegrated system. The estimation involves regressing one of the $I(1)$ variables on the remaining $I(1)$ variables, the $I(0)$ variables, leads $(p)$ and lags $(-p)$ of the first difference of the $I(1)$ variables, and a constant. By doing so, it corrects for potential endogeneity problems and small sample bias, and provides estimates of the cointegrating vector which are asymptotically efficient. ${ }^{4}$

\section{Estimation Results}

\subsection{Long-run and short-run ARDL estimates}

Table 1 presents the results for the pollution function estimated using the ARDL estimator. The table shows the results obtained for three models, where each model corresponds to the estimation results using different measures of research intensity. In view of sample size, we consider only one lag in the estimation. The choice of this lag length appears to be consistent with the optimal lag suggested by standard information criteria such as AIC and SBC.

It is evident that energy consumption enters the long-run pollution equation significantly at the one percent level with the expected sign. Specifically, the coefficients of $\ln E_{t}$ are found to be in the range of 1.073 to 1.104 . Using the Wald tests, the null that the parameter of energy consumption is equal to one (or $H_{0}: \beta_{1}=1$ in Eq. 7) cannot be rejected at the five percent significance level, suggesting that there is a one-to-one relationship between energy use and $\mathrm{CO}_{2}$ emissions in China. The finding of a positive effect of energy use is consistent with Liu (2005) and Ang ( 2007, 2008), among others. The income variable $\left(\ln Y_{t}\right)$, however, is found to have no statistically significant impact on the level of pollution, regardless of how research intensity is measured.

\footnotetext{
${ }^{4}$ All underlying variables are found to be either $I(0)$ or $I(1)$, and this allows legitimate use of the ARDL and DOLS estimators. The unit root test results are not reported here to conserve space, but they are available upon request.
} 
Trade openness $\left(\ln T O_{t}\right)$ is found to have a positive impact on pollution, suggesting that a more liberalized trade sector tends to harm the environment. This finding is highly plausible for China given that the negative scale effect associated with trade liberalization on the environment is likely to outweigh the positive technique effect. Moreover, given China's status as a developing country, the pollution haven hypothesis suggests that its composition effect of trade is likely to degrade the environment. Hence, the overall effect of free trade on the environment is likely to be negative (see also Antweiler et al., 2001; Cole and Elliott, 2003).

Turning to the measures of $\mathrm{R} \& \mathrm{D}$ intensity $\left(\ln (X / Q)_{t-1}\right)$ and distance to the frontier $\left(\ln D T F_{t-1}\right)$, the results strongly suggest that more R\&D activity and the transfer of foreign technology are effective mechanisms for abating pollution. Our estimates show that research intensity has both direct and indirect effects on $\mathrm{CO}_{2}$ emissions. Holding the indirect effect constant, the results show that research intensity is found to have a direct negative effect on $\mathrm{CO}_{2}$ emissions in China, with a negative long-run elasticity in the range of $0.154-0.281$. With regard to its indirect effect, the interaction term is found to be statistically significant and has the expected negative sign.

In this connection, it can be inferred that China's ability to assimilate foreign technical know-how can be enhanced through more R\&D investment, and this highlights the important role of local $R \& D$ capability as an effective channel for tapping into technology developed in the frontier countries (see $\mathrm{Hu}$ et al., 2005). This interpretation is obvious when we obtain the derivative of $\ln C_{t}$ with respect to $\ln (X / Q)_{t-1}$. In Model $\mathrm{A}$, this gives $-0.179-1.767 \ln (X / Q)_{t-1}$. Our results imply that more $\mathrm{R} \& \mathrm{D}$ spending will result in lower pollution via two channels: 1) directly mitigating the environmental damage by facilitating the innovation of new production techniques that help abate pollutant emissions; and 2) enabling firms to more effectively assimilate green technology developed elsewhere, thus helping narrow the technology gap between the frontier and the domestic economy. With regard to the direct effect of distance to the frontier, a one percent increase in the technology gap tends to reduce pollution by 5.639 to 9.720 percent, holding research intensity constant. This finding suggests that China can gain significant benefits by using technology developed elsewhere to help combat pollution. The coefficients associated with Reg are found to be negative and significant in all models. Thus, environmental regulation appears to be an effective device in containing $\mathrm{CO}_{2}$ emissions. 
Table 1: ARDL estimates of the $\mathrm{CO}_{2}$ emissions equation (1953-2006)

\begin{tabular}{|c|c|c|c|c|c|c|}
\hline & \multicolumn{2}{|c|}{$\frac{\text { Model A }}{(X / Q)_{t}=(R / Y)_{t}}$} & \multicolumn{2}{|c|}{$\frac{\text { Model B }}{(X / Q)_{t}=(R / A L)_{t}}$} & \multicolumn{2}{|c|}{$\frac{\text { Model C }}{(X / Q)_{t}=(R / A H L)_{t}}$} \\
\hline & Coeff. & $p$-value & Coeff. & $p$-value & Coeff. & $p$-value \\
\hline \multicolumn{7}{|c|}{ I. The long-run relationship $\left(\right.$ Dep. $\left.=\ln C_{t}\right)$} \\
\hline Intercept & $-2.206^{* * *}$ & 0.000 & $-2.327^{* *}$ & 0.013 & $-2.055^{* * *}$ & 0.000 \\
\hline $\ln E_{t}$ & $1.104^{* * *}$ & 0.000 & $1.081^{* * *}$ & 0.000 & $1.073^{* * *}$ & 0.000 \\
\hline $\ln Y_{t}$ & 0.008 & 0.889 & 0.057 & 0.484 & 0.012 & 0.820 \\
\hline $\ln T O_{t}$ & $0.128^{* * *}$ & 0.000 & $0.138^{* * *}$ & 0.002 & $0.140^{* * *}$ & 0.000 \\
\hline $\ln (X / Q)_{t-1}$ & $-0.179^{* * *}$ & 0.000 & $-0.281^{* * *}$ & 0.001 & $-0.154^{* * *}$ & 0.000 \\
\hline $\ln D T F_{t-1}$ & $-9.720^{* * *}$ & 0.000 & $-6.989^{* *}$ & 0.010 & $-5.639^{* * *}$ & 0.000 \\
\hline $\ln (X / Q)_{t-1} \times \ln D T F_{t-1}$ & $-1.767^{* * *}$ & 0.000 & $-3.186^{* * *}$ & 0.001 & $-1.381^{* * *}$ & 0.000 \\
\hline $\operatorname{Reg}$ & $-0.083^{* *}$ & 0.024 & $-0.118^{*}$ & 0.053 & $-0.092^{* * *}$ & 0.008 \\
\hline
\end{tabular}

II. The short-run dynamics $\left(\right.$ Dep. $\left.=\Delta \ln C_{t}\right)$

\begin{tabular}{cllllll}
\hline Intercept & $-1.197^{* * *}$ & 0.003 & $-0.800^{*}$ & 0.053 & $-1.166^{* * *}$ & 0.002 \\
$E C T_{t-1}$ & $-0.545^{* * *}$ & 0.000 & $-0.344^{* * *}$ & 0.001 & $-0.567^{* * *}$ & 0.000 \\
$\Delta \ln E_{t}$ & $0.601^{* * *}$ & 0.000 & $0.617^{* * *}$ & 0.000 & $0.609^{* * *}$ & 0.000 \\
$\Delta \ln Y_{t}$ & 0.004 & 0.890 & 0.020 & 0.508 & 0.007 & 0.822 \\
$\Delta \ln T O_{t}$ & $0.070^{* * *}$ & 0.000 & $0.047^{* * *}$ & 0.015 & $0.080^{* * *}$ & 0.000 \\
$\Delta \ln (X / Q)_{t-1}$ & $-0.097^{* * *}$ & 0.000 & $-0.097^{* * *}$ & 0.000 & $-0.087^{* * *}$ & 0.000 \\
$\Delta \ln D T F_{t-1}$ & $-5.293^{* * *}$ & 0.000 & $-2.404^{* * *}$ & 0.001 & $-3.200^{* * *}$ & 0.000 \\
$\Delta[\ln (X / Q) \mathrm{x}$ & $-0.962^{* * *}$ & 0.000 & $-1.096^{* * *}$ & 0.000 & $-0.784^{* * *}$ & 0.000 \\
$\ln$ DTF $]_{t-1}$ & $-0.045^{* * *}$ & 0.013 & $-0.040^{* * *}$ & 0.036 & $-0.052^{* * *}$ & 0.003 \\
$\Delta R e g$ & Test-stat. & $p$-value & Test-stat. & $p$-value & Test-stat. & $p$-value \\
\hline III. Diagnostic checks & 1.028 & 0.311 & 1.205 & 0.272 & 1.613 & 0.204 \\
\hline$\chi_{\text {SERIAL }}^{2}$ & 3.732 & 0.881 & 3.736 & 0.880 & 4.177 & 0.841 \\
$\chi_{\text {WHITE }}^{2}$ & 0.208 & 0.649 & 0.293 & 0.588 & 0.203 & 0.652 \\
$\chi_{\text {ARCH }}^{2}$ & 0.256 & 0.613 & 0.159 & 0.690 & 0.672 & 0.413 \\
$\chi_{\text {RESET }}^{2}$ & & & & & & \\
\hline \hline
\end{tabular}

Notes: $\chi_{\text {NORMAL }}^{2}$ refers to the Jarque-Bera statistic of the test for normal residuals, $\chi_{\text {SERIAL }}^{2}$ is Breusch-Godfrey LM test statistics for no first-order serial correlation, respectively, $\chi_{\text {WHITE }}^{2}$ denotes the White's test statistic to test for homoskedastic errors, $\chi_{A R C H}^{2}$ is the Engle's test statistic for no autoregressive conditional heteroskedasticity and $\chi_{\text {RESET }}^{2}$ is the Ramsey's test statistic for no functional misspecification. *, ** and *** indicate $10 \%, 5 \%$ and $1 \%$ levels of significance, respectively. 
The short-run dynamics of the $\mathrm{CO}_{2}$ emissions function are reported in panel II of Table 1. Similar to the long-run results, income growth is found to have no statistically significant impact on the increase in pollution. In first-differenced form, the variables have expected signs, consistent with the results obtained for the long-run models. The magnitudes of all the coefficients are smaller than their long-run counterparts, suggesting that these variables have stronger effects on pollution in the long run. For instance, in Model A, a one unit increase in research intensity is associated with a 0.179 unit reduction in pollution in the long run. However, in the short run, a one percentage point increase in the growth rate of research intensity is correlated with only a 0.097 percentage point decrease in the growth rate of $\mathrm{CO}_{2}$ emissions.

The error-correction term (ECT) captures the evolution process on the variable of concern, in this case $\Delta \ln E_{t}$, by which agents adjust for prediction errors made in the last period. The coefficients on $E C T_{t-1}$, which measure the speed of adjustment back to the long-run equilibrium value, are statistically significant at the one percent level and correctly signed, i.e., negative. This implies that an error-correction mechanism exists in the $\mathrm{CO}_{2}$ emissions function so that the deviation from long-run equilibrium has a significant impact on the growth rate of pollution. This provides some evidence supporting the presence of the underlying relationship in the long run. It is found that the economy will adjust at a speed of 34.4 percent to 56.7 percent a year to restore equilibrium when there is a shock to the steady-state relationship.

\subsection{Robustness checks}

The results reported in panel III of Table 1 show that the regression specifications fit remarkably well. In particular, in all models, we do not find any evidence of serial correlation, heteroskedasticity, autoregressive conditional heteroskedasticity and functional misspecification at the conventional levels of significance. The structural stability of the emissions function is examined using the cumulative sum (CUSUM) tests on the recursive residuals. ${ }^{5}$ The test is able to detect systematic changes in the regression coefficients. Figure 2 shows that the statistics generally lie within or on the five percent confidence interval bands, suggesting no structural instability in the residuals of the emissions equation.

\footnotetext{
${ }^{5}$ We have also tested for the presence of structural breaks by interacting all variables (except trade openness) in the equation with a dummy variable $(d)$ to capture the effects of the reforms that took place since 1978. $d$ equals 1 for the post-reform period and is set to zero before the reform. The reform date is alternatively assumed to be 1978 , 1980 and 1982. With no exception, all these interaction terms turn out to be statistically insignificant, providing some support that our results are not distorted by the regime shifts that have occurred following the reform episode.
} 
Figure 2: Plots of cumulative sum of recursive residuals
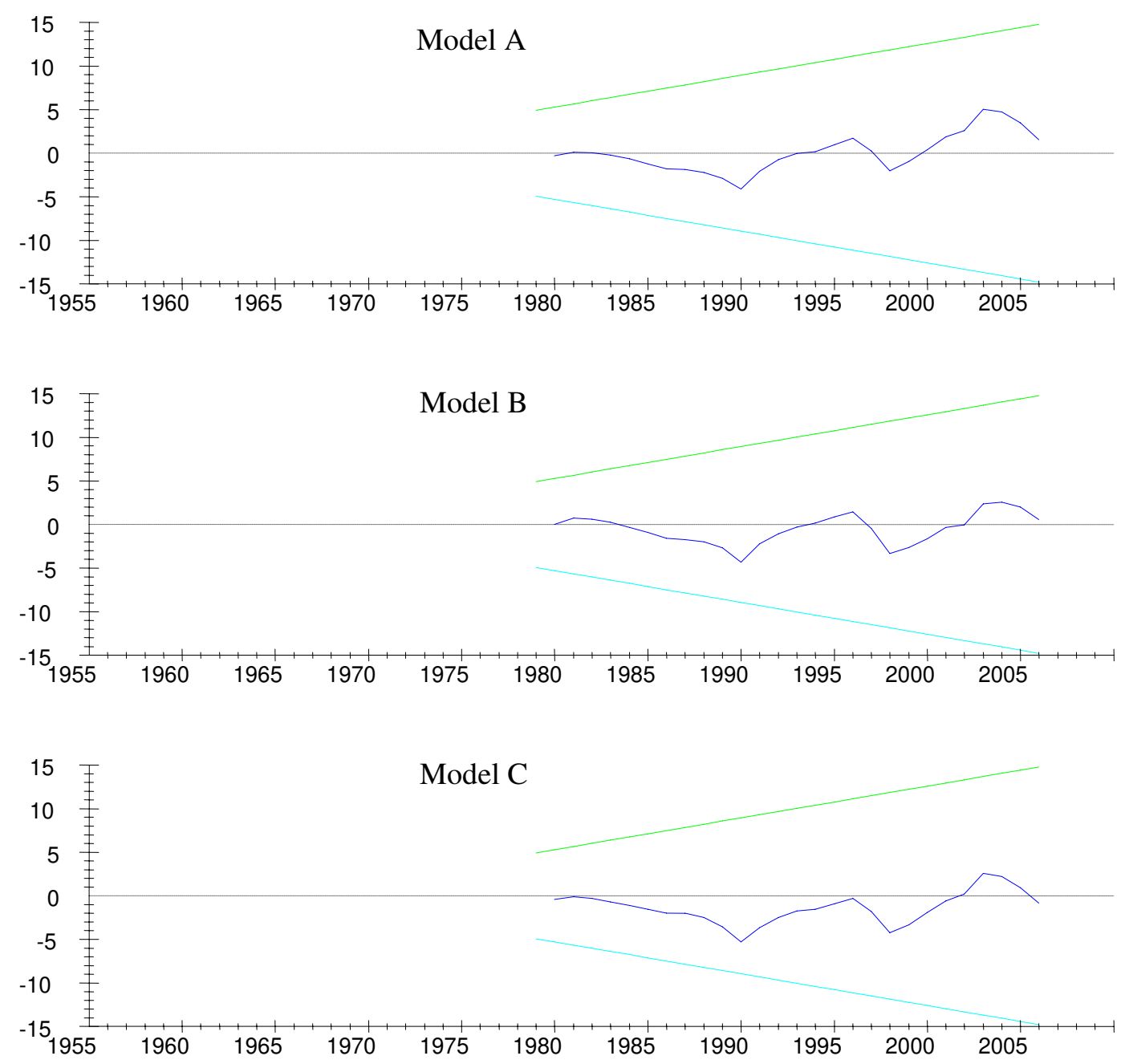

Notes: The straight lines represent critical bounds at the 5\% significance level.

\subsection{Alternative estimators}

The sensitivity of the results is further assessed using three other estimators, namely the FM-OLS procedure of Phillips and Hansen (1990), the FM-UECM estimator of Inder (1993) and the DOLS procedure of Stock and Watson (1993). As Table 2 shows, these approaches give very similar results compared to those estimated using the ARDL approach. Although the magnitude of the coefficients shows some small variations, the qualitative aspects of the results are, by and large, consistent with those obtained using the ARDL estimator. An exception is that income is found to have a statistically positive effect on pollution when the models are estimated using the approaches that involve a fully-modified procedure. Importantly, the key findings that research intensity, distance to the frontier and their interaction help reduce $\mathrm{CO}_{2}$ emissions remain unaltered. The results are insensitive to choice of the research intensity measures. The 
short-run results and diagnostic tests are also similar to those obtained using the ARDL estimation technique, and hence not reported here for brevity. We therefore conclude that the results are quite robust overall to the choice of estimators.

Table 2: Alternative estimates for the $\mathrm{CO}_{2}$ emissions equation (1953-2006)

\begin{tabular}{|c|c|c|c|c|c|c|}
\hline \multirow[b]{2}{*}{ I. $F M-O L S$} & \multicolumn{2}{|c|}{$\frac{\text { Model A }}{(X / Q)_{t}=(R / Y)_{t}}$} & \multicolumn{2}{|c|}{$\frac{\text { Model B }}{(X / Q)_{t}=(R / A L)_{t}}$} & \multicolumn{2}{|c|}{$\frac{\text { Model C }}{(X / Q)_{t}=(R / A H L)_{t}}$} \\
\hline & Coeff. & $p$-value & Coeff. & $p$-value & Coeff. & $p$-value \\
\hline Intercept & $-2.800^{* * *}$ & 0.000 & $-2.925^{* * *}$ & 0.000 & $-2.641^{* * *}$ & 0.000 \\
\hline $\ln E_{t}$ & $1.076^{* * *}$ & 0.000 & $1.048^{* * *}$ & 0.000 & $1.054^{* * *}$ & 0.000 \\
\hline $\ln Y_{t}$ & $0.098^{* *}$ & 0.019 & $0.150^{* * *}$ & 0.002 & $0.091^{* *}$ & 0.024 \\
\hline $\ln T O_{t}$ & $0.109^{* * *}$ & 0.000 & $0.112^{* * *}$ & 0.000 & $0.118^{* * *}$ & 0.000 \\
\hline $\ln (X / Q)_{t-1}$ & $-0.133^{* * *}$ & 0.000 & $-0.133^{* * *}$ & 0.000 & $-0.121^{* * *}$ & 0.000 \\
\hline $\ln D T F_{t-1}$ & $-5.770^{* * *}$ & 0.000 & -1.245 & 0.193 & $-3.060^{* * *}$ & 0.001 \\
\hline $\ln (X / Q)_{t-1} \times \ln D T F_{t-1}$ & $-1.285^{* * *}$ & 0.000 & $-1.337^{* * *}$ & 0.001 & $-1.038^{* * *}$ & 0.000 \\
\hline $\operatorname{Reg}$ & -0.037 & 0.153 & -0.029 & 0.318 & $-0.049^{* *}$ & 0.046 \\
\hline \multicolumn{7}{|l|}{ II. FM-UECM } \\
\hline Intercept & $-2.699^{* * *}$ & 0.000 & $-2.775^{* * *}$ & 0.000 & $-2.478^{* * *}$ & 0.000 \\
\hline $\ln E_{t}$ & $1.088^{* * *}$ & 0.000 & $1.064^{* * *}$ & 0.000 & $1.067^{* * *}$ & 0.000 \\
\hline $\ln Y_{t}$ & $0.094^{* * *}$ & 0.000 & $0.141^{* * *}$ & 0.000 & $0.077^{* * *}$ & 0.000 \\
\hline $\ln T O_{t}$ & $0.097^{* * *}$ & 0.000 & $0.099^{* * *}$ & 0.000 & $0.106^{* * *}$ & 0.000 \\
\hline $\ln (X / Q)_{t-1}$ & $-0.130^{* * *}$ & 0.000 & $-0.131^{* * *}$ & 0.000 & $-0.122^{* * *}$ & 0.000 \\
\hline $\ln D T F_{t-1}$ & $-5.634^{* * *}$ & 0.000 & $-1.196^{* * *}$ & 0.000 & $-3.045^{* * *}$ & 0.000 \\
\hline $\ln (X / Q)_{t-1} \times \ln D T F_{t-1}$ & $-1.247^{* * *}$ & 0.000 & $-1.267^{* * *}$ & 0.000 & $-0.993^{* * *}$ & 0.000 \\
\hline Reg & $-0.026^{*}$ & 0.073 & -0.016 & 0.279 & $-0.036^{* *}$ & 0.012 \\
\hline \multicolumn{7}{|l|}{ III. DOLS } \\
\hline Intercept & -0.912 & 0.322 & $-1.879^{*}$ & 0.096 & -1.090 & 0.166 \\
\hline $\ln E_{t}$ & $1.175^{* * *}$ & 0.000 & $1.101^{* * *}$ & 0.000 & $1.128^{* * *}$ & 0.000 \\
\hline $\ln Y_{t}$ & -0.121 & 0.216 & 0.032 & 0.756 & -0.081 & 0.325 \\
\hline $\ln T O_{t}$ & $0.153^{* * *}$ & 0.000 & $0.144^{* * *}$ & 0.001 & $0.160^{* * *}$ & 0.000 \\
\hline $\ln (X / Q)_{t-1}$ & $-0.193^{* * *}$ & 0.000 & $-0.201^{* * * *}$ & 0.001 & $-0.162^{* * *}$ & 0.000 \\
\hline $\ln D T F_{t-1}$ & $-12.295^{* * *}$ & 0.000 & $-5.001^{* *}$ & 0.028 & $-7.541^{* * *}$ & 0.000 \\
\hline $\ln (X / Q)_{t-1} \times \ln D T F_{t-1}$ & $-1.978^{* * *}$ & 0.000 & $-2.273^{* * *}$ & 0.001 & $-1.592^{* * *}$ & 0.000 \\
\hline $\operatorname{Reg}$ & $-0.079^{* * *}$ & 0.006 & $-0.075^{* *}$ & 0.027 & $-0.084^{* * *}$ & 0.002 \\
\hline
\end{tabular}

Notes: the short-run dynamics and the diagnostic test results are not reported to conserve space. They are available upon request. $*, * *$ and $* * *$ indicate $10 \%, 5 \%$ and $1 \%$ levels of significance, respectively. 


\subsection{Alternative specification}

Our underlying model assumes so far that all the right-hand-side variables in Eq. (7) have a direct effect on $\mathrm{CO}_{2}$ emissions. However, the model may be misspecified since some of these variables may act indirectly on $\mathrm{CO}_{2}$ emissions through the channel of energy demand rather than operating directly on $\mathrm{CO}_{2}$ emissions once we control for energy demand. In light of this, we also estimate a simultaneous equation system to further examine the robustness of the results. ${ }^{6}$ For the first equation, we assume that per capita pollutant emission $\left(C_{t}\right)$ is a function of per capita energy consumption $\left(E_{t}\right)$, trade openness $\left(T O_{t}\right)$, research intensity $\left[(X / Q)_{t}\right]$ and a dummy variable capturing the effect of environmental regulation $(\operatorname{Reg})$, as follows:

$$
\ln C_{t}=\chi_{0}+\chi_{1} \ln E_{t}+\chi_{2} \ln T O_{t}+\chi_{3} \ln (X / Q)_{t-1}+\chi_{4} \operatorname{Reg}+\mu_{t}
$$

The second equation, i.e., the energy demand function, is postulated to take the form of Eq. (10). Here, per capita energy consumption $\left(E_{t}\right)$ is specified as a function of per capita real income $\left(Y_{t}\right)$, distance to the frontier $\left(D T F_{t}\right)$ and absorptive capacity $\left[(X / Q)_{t-1} \times \mathrm{DTF}_{t-1}\right]$, as follows: ${ }^{7}$

$$
\ln E_{t}=\delta_{0}+\delta_{1} \ln Y+\delta_{2} \ln D T F_{t-1}+\delta_{3}[\ln (X / Q) \mathrm{x} \ln D T F]_{t-1}+v_{t}
$$

Under this simultaneous framework, we assume that more $R \& D$ investment encourages the innovation of new production techniques or green technology that helps curb $\mathrm{CO}_{2}$ emissions, and hence $\chi_{3}$ is expected to be negative. Both technological backwardness and absorptive capacity of the domestic economy enables the adoption of energy-efficient technology developed by the frontier countries, and this effectively reduces energy consumption. Thus, both $\delta_{2}$ and $\delta_{3}$ are expected to carry a negative sign.

Eqs. (9) and (10) are jointly estimated using the seemingly unrelated regression (SUR) (or Zeller's method) and the full information maximum likelihood (FIML) estimators to obtain the parameter estimates of the system. The former accounts for both heteroskedasticity and

\footnotetext{
${ }^{6}$ We thank an anonymous referee for drawing our attention to this point and for recommending this alternative modelling approach.

${ }^{7}$ We have also considered research intensity in the energy demand equation due to Fisher-Vanden et al. (2004) and Fisher-Vanden and Jefferson (2008). However, the inclusion of this variable gives unsatisfactory regression results and therefore it is omitted in the specification.
} 
contemporaneous correlation in the residuals across all equations whereas the latter is a fully efficient estimator which assumes that the contemporaneous errors have a joint normal distribution. The estimates reported in Table 3 show that our earlier results are, by and large, insensitive to this alternative modelling framework. Although the legal dummy and distance to the frontier become insignificant in some cases, all variables continue to have their expected signs and are highly significant. The system estimates are also robust to different measures of research intensity and the choice of estimators.

Table 3: SUR and FIML estimates for the simultaneous equation system

\begin{tabular}{|c|c|c|c|c|c|c|}
\hline & \multicolumn{2}{|c|}{$\frac{\text { Model A }}{(X / Q)_{t}}=(R / Y)_{t}$} & \multicolumn{2}{|c|}{$\frac{\text { Model B }}{(X / Q)_{t}}=(R / A L)_{t}$} & \multicolumn{2}{|c|}{$\frac{\text { Model C }}{(X / Q)_{t}}=(R / A H L)_{t}$} \\
\hline & SUR & FIML & SUR & FIML & SUR & FIML \\
\hline \multicolumn{7}{|c|}{ I. The Emissions Function (Dep. $=\ln C_{t}$ ) } \\
\hline Intercept & $\begin{array}{l}-1.228^{* * * *} \\
(0.000)\end{array}$ & $\begin{array}{l}-1.095^{* * *} \\
(0.000)\end{array}$ & $\begin{array}{l}-1.101^{\text {**** }} \\
(0.000)\end{array}$ & $\begin{array}{l}-0.985^{* * *} \\
(0.000)\end{array}$ & $\begin{array}{l}-1.329^{* * *} \\
(0.000)\end{array}$ & $\begin{array}{l}-1.239^{* * *} \\
(0.000)\end{array}$ \\
\hline $\ln E_{t}$ & $\begin{array}{l}1.128^{* * *} \\
(0.000)\end{array}$ & $\begin{array}{l}1.152^{* * *} \\
(0.000)\end{array}$ & $\begin{array}{l}1.134^{* * *} \\
(0.000)\end{array}$ & $\begin{array}{l}1.153^{* * *} \\
(0.000)\end{array}$ & $\begin{array}{l}1.115^{* * *} \\
(0.000)\end{array}$ & $\begin{array}{l}1.130^{* * * *} \\
(0.000)\end{array}$ \\
\hline $\ln T O_{t}$ & $\begin{array}{l}0.127^{* * *} \\
(0.000)\end{array}$ & $\begin{array}{l}0.112^{* * *} \\
(0.000)\end{array}$ & $\begin{array}{l}0.131^{* * *} \\
(0.000)\end{array}$ & $\begin{array}{l}0.119^{* * *} \\
(0.000)\end{array}$ & $\begin{array}{l}0.113^{* * *} \\
(0.000)\end{array}$ & $\begin{array}{l}0.103^{* * *} \\
(0.000)\end{array}$ \\
\hline $\ln (X / Q)_{t-1}$ & $\begin{array}{l}-0.031^{* * *} \\
(0.000)\end{array}$ & $\begin{array}{l}-0.035^{* * *} \\
(0.003)\end{array}$ & $\begin{array}{l}-0.035^{* * *} \\
(0.000)\end{array}$ & $\begin{array}{l}-0.040^{* * *} \\
(0.006)\end{array}$ & $\begin{array}{l}-0.040^{* * *} \\
(0.000)\end{array}$ & $\begin{array}{l}-0.043^{* * *} \\
(0.002)\end{array}$ \\
\hline $\operatorname{Reg}$ & $\begin{array}{l}-0.152^{* *} \\
(0.041)\end{array}$ & $\begin{array}{l}-0.107 \\
(0.245)\end{array}$ & $\begin{array}{l}-0.128^{*} \\
(0.052)\end{array}$ & $\begin{array}{l}-0.101 \\
(0.232)\end{array}$ & $\begin{array}{l}-0.081 \\
(0.317)\end{array}$ & $\begin{array}{l}-0.048 \\
(0.678)\end{array}$ \\
\hline \multicolumn{7}{|c|}{ II. The Energy Demand Function $\left(\right.$ Dep. $\left.=\ln E_{t}\right)$} \\
\hline Intercept & $\begin{array}{l}-14.326^{* * *} \\
(0.000)\end{array}$ & $\begin{array}{l}-14.237^{* * * *} \\
(0.000)\end{array}$ & $\begin{array}{l}-13.769^{* * *} \\
(0.000)\end{array}$ & $\begin{array}{l}-13.747^{* * *} \\
(0.000)\end{array}$ & $\begin{array}{l}-15.651^{* * * *} \\
(0.000)\end{array}$ & $\begin{array}{l}-15.571^{* * * *} \\
(0.000)\end{array}$ \\
\hline $\ln Y_{t}$ & $\begin{array}{l}0.971^{* * *} \\
(0.000)\end{array}$ & $\begin{array}{l}0.962^{* * * *} \\
(0.000)\end{array}$ & $\begin{array}{l}0.905^{* * *} \\
(0.000)\end{array}$ & $\begin{array}{l}0.905^{* * *} \\
(0.000)\end{array}$ & $\begin{array}{l}1.181^{* * *} \\
(0.000)\end{array}$ & $\begin{array}{l}1.170^{* * * *} \\
(0.000)\end{array}$ \\
\hline $\ln D T F_{t-1}$ & $\begin{array}{l}-10.792^{* * *} \\
(0.000)\end{array}$ & $\begin{array}{l}-10.167^{* * *} \\
(0.009)\end{array}$ & $\begin{array}{l}-1.572 \\
(0.365)\end{array}$ & $\begin{array}{l}-1.124 \\
(0.677)\end{array}$ & $\begin{array}{l}-3.466 \\
(0.178)\end{array}$ & $\begin{array}{l}-3.443 \\
(0.282)\end{array}$ \\
\hline $\ln (X / Q)_{t-1} \times \ln D T F_{t-1}$ & $\begin{array}{l}-3.219^{* * *} \\
(0.000)\end{array}$ & $\begin{array}{l}-3.171^{* * *} \\
(0.000)\end{array}$ & $\begin{array}{l}-3.464^{* * *} \\
(0.000)\end{array}$ & $\begin{array}{l}-3.424^{* * *} \\
(0.000)\end{array}$ & $\begin{array}{l}-3.284^{* * *} \\
(0.000)\end{array}$ & $\begin{array}{l}-3.310^{* * *} \\
(0.000)\end{array}$ \\
\hline
\end{tabular}

Notes: Figures in parenthesis indicate the $p$-values. $*, * *$ and $* * *$ indicate $10 \%, 5 \%$ and $1 \%$ levels of significance, respectively.

\section{Summary and Conclusions}

This study was motivated by the observation of a rapid deterioration in the environmental quality of China in recent years along with its strong growth performance, and the lack of any previous attempts to analyze the underlying forces influencing $\mathrm{CO}_{2}$ emissions at 
the aggregate level. Amidst active debate on global warming issues, the present study provides timely information to guide policy formulation for China as well as other developing countries.

The analytical framework combines modern growth theoretical underpinnings with the environmental literature so that we can focus the analysis on the roles of R\&D activity and technology transfer in reducing pollution. Using aggregate data for China for more than half a century, the empirical results show that an increase in energy use and trade intensity contribute to higher $\mathrm{CO}_{2}$ emissions in China. On the other hand, $\mathrm{CO}_{2}$ emissions decrease with increases in research activity, distance to the technological frontier and their interaction that reflects the ability of China to absorb foreign technology. Given the significant interaction between R\&D intensity and the technology gap, increased domestic R\&D activity will help the domestic economy to assimilate technology developed in the leading countries more effectively. Thus, research intensity exerts both direct and indirect beneficial influences in abating $\mathrm{CO}_{2}$ emissions. There is also some evidence that higher aggregate demand induces more $\mathrm{CO}_{2}$ emissions but the adoption of more stringent environmental regulations helps in abating them.

However, it should be highlighted that since the estimation results are based on time series aggregate data, our estimates may not be consistent with analysis conducted at the provincial level, which provides more degrees of freedom in estimation but involves a much shorter time horizon. The use of provincial data is beyond the scope of the present paper and will be left for future research. Notwithstanding this limitation, the findings of this paper are broadly in line with the literature and have important implications for policy design. To the extent that research intensity and its interaction with distance to the frontier technology have a positive effect in reducing $\mathrm{CO}_{2}$ emissions, policies that encourage more research activity will not only help contain pollution directly through facilitating more innovation in production techniques that emit less pollutions, but will also enable China to more effectively absorb technology developed elsewhere and thereby catch up to the frontier's green technology. Thus, increasing research efforts have dual positive effects in containing pollution. These effects are expected to continue given that China is unlikely to surpass the world technological leader in the near future. Finally, the results in this study also highlight that modern R\&D-based endogenous growth models can be applied to understand issues related to environmental pollution even in the context of developing economies. 


\section{References}

Ades, A.F. and Glaeser, E.L. (1999). "Evidence on Growth, Increasing Returns and the Extent of the Market." Quarterly Journal of Economics 114, pp. 1025-1045.

Aghion, P. and Howitt, P. (1992). "A Model of Growth through Creative Destruction." Econometrica 60, pp. 323-351.

(1998). Endogenous Growth Theory. Cambridge: MIT Press.

Alesina, A.; Spolaore, E. and Wacziarg, R. (2000). "Economic Integration and Political Disintegration." American Economic Review 90, pp. 1276-1296.

Ang, J.B. (2007). "CO2 Emissions, Energy Consumption, and Output in France." Energy Policy 35, pp. 4772-4778.

(2008). "The Long-run Relationship between Economic Development, Pollutant Emissions, and Energy Consumption: Evidence from Malaysia." Journal of Policy Modeling 30, pp. 271-278.

Antweiler, W.; Brian, C.R. and Scott, T. (2001). "Is free trade good for the environment? ." American Economic Review 91, pp. 877-908.

Auffhammer, M. and Carson, R.T. (2008). "Forecasting the Path of China's CO2 Emissions Using Province-Level Information." Journal of Environmental Economics and Management 55, pp. 229-247.

Bernard, A.B. and Jones, C.I. (1996a). "Comparing Apples to Oranges: Productivity Convergence and Measurement Across Industries and Countries." American Economic Review 86, pp. 1216-1238.

(1996b). "Productivity Across Industries and Countries: Time Series Theory and Evidence." Review of Economics and Statistics 78, pp. 135-146.

Bewley, R. (1979). "The Direct Estimation of the Equilibrium Response in a Linear Dynamic Model." Economics Letters 3, pp. 357-361.

Cameron, G.; Proudman, J. and Redding, S. (2005). "Technological Convergence, R\&D, Trade and Productivity Growth." European Economic Review 49, pp. 775-807.

Chan, H. and Lee, S. (1996). "Forecasting the Demand for Energy in China." Energy Journal 17, pp. 19-30.

Choudhri, E.U. and Hakura, D.S. (2000). "International Trade and Productivity Growth: Exploring the Sectoral Effects for Developing Countries." IMF Staff Papers 47, pp. 30-53.

Coe, D.T. and Helpman, E. (1995). "International R\&D spillovers." European Economic Review 39, pp. 859-897. 
Coe, D.T.; Helpman, E. and Hoffmaister, A.W. (1997). "North-South R\&D Spillovers." Economic Journal 107, pp. 134-149.

Cole, M.A. and Elliott, R.J.R. (2003). "Determining the Trade-Environment Composition Effect: The Role of Capital, Labor and Environmental Regulations " Journal of Environmental Economics and Management 46, pp. 363-383.

Cole, M.A.; Elliott, R.J.R. and Shimamoto, K. (2005). "Industrial Characteristics, Environmental Regulation and Air Pollution: An Analysis of the UK Manufacturing Sector." Journal of Environmental Economics and Management 50, pp. 121-143.

Cole, M.A.; Elliott, R.J.R. and Wu, S. (2008). "Industrial Activity and the Environment in China: An Industry-Level Analysis." China Economic Review 19, pp. 393-408.

Crompton, P. and Wu, Y. (2005). "Energy Consumption in China: Past Trends and Future Directions." Energy Economics 27, pp. 195-208.

Dinopoulos, E. and Thompson, P. (1998). "Schumpeterian Growth without Scale Effects." Journal of Economic Growth 3, pp. 313-335.

Fisher-Vanden, K. and Jefferson, G.H. (2008). "Technology Diversity and Development: Evidence from China's Industrial Enterprises." Journal of Comparative Economics 36, pp. 658672.

Fisher-Vanden, K.; Jefferson, G.H.; Liu, H. and Tao, Q. (2004). "What Is Driving China's Decline in Energy Intensity?" Resource and Energy Economics 26, pp. 77-97.

Friedl, B. and Getzner, M. (2003). "Determinants of CO2 Emissions in A Small Open Economy." Ecological Economics 45, pp. 133-148.

Griffith, R.; Redding, S. and Reenen, J.V. (2003). "R\&D and Absorptive Capacity: Theory and Empirical Evidence." Scandinavian Journal of Economics 105, pp. 99-118.

Griffith, R.; Redding, S. and Reenen, J.v. (2004). "Mapping the Two Faces of R\&D: Productivity Growth in a Panel of OECD Industries." Review of Economics and Statistics 86, pp. 883-895.

Grossman, G.M. and Helpman, E. (1990). "Comparative Advantage and Long-Run Growth." American Economic Review 80, pp. 796-815.

(1991a). "Endogenous Product Cycles." Economic Journal 101, pp. 1214-1229.

(1991b). "Quality Ladders in the Theory of Growth." Review of Economic Studies 58, pp. 43-61.

Guellec, D. and De la Potterie, B.V.P. (2004). "From R\&D to Productivity Growth: Do the Institutional Settings and the Source of Funds of R\&D Matter?" Oxford Bulletin of Economics and Statistics 66, pp. 353-378. 
Ha, J. and Howitt, P. (2007). "Accounting for Trends in Productivity and R\&D: A Schumpeterian Critique of Semi-Endogenous Growth Theory." Journal of Money, Credit and Banking 39, pp. 733-774.

Holtz-Eakin, D. and Selden, T.M. (1995). "Stoking the fires? CO2 emissions and economic growth." Journal of Public Economics 57, pp. 85-101.

Howitt, P. (1999). "Steady Endogenous Growth with Population and R\&D Inputs Growing." Journal of Political Economy 107, pp. 715-730.

(2000). "Endogenous Growth and Cross-Country Income Differences." American Economic Review 90, pp. 829-846.

Hu, A.G.Z.; Jefferson, G.H. and Jinchang, Q. (2005). "R\&D and Technology Transfer: FirmLevel Evidence from Chinese Industry." Review of Economics and Statistics 87, pp. 780-786.

Inder, B. (1993). "Estimating Long-Run Relationships in Economics: A Comparison of Different Approaches." Journal of Econometrics 57, pp. 53-68.

Liu, X. (2005). "Explaining the Relationship between CO2 Emissions and National Income The Role of Energy Consumption." Economics Letters 87, pp. 325-328.

Madsen, J.B.; Saxena, S. and Ang, J.B. (2008). "The Indian Growth Miracle and Endogenous Growth." The Australian National University, Center for Applied Macroeconomic Analysis (CAMA) Working Papers.

Martinez-Zarzoso, I. and Bengochea-Morancho, A. (2004). "Pooled mean group estimation of an environmental Kuznets curve for CO2." Economics Letters 82, pp. 121-126.

National-Bureau-of-Statistics-of-China (1999). Comprehensive Statistical Data and Materials on 50 Years of New China. Beijing: China Statistics Press.

(various issues). China Statistical Yearbook. Beijing: China Statistics Press.

Nielsen, C.P. and Ho, M.S. (2007). "Air Pollution and Health Damages in China: An Introduction and Review," Ho, M. S. and Nielsen, C. P. (Ed), In: Clearing the Air: The Health and Economic Damages of Air Pollution in China. Cambridge and London: MIT Press, 3-50.

Peretto, P. (1998). "Technological Change and Population Growth." Journal of Economic Growth 3, pp. 283-311.

Pesaran, M.H. and Shin, Y. (1999). "An Autoregressive Distributed-Lag Modelling Approach to Cointegration Analysis," Strom, S. (Ed), In: Econometrics and Economic Theory in the Twentieth Century: The Ragnar Frisch Centennial Symposium. Cambridge: Cambridge University Press, 371-413.

Phillips, P.C.B. and Hansen, B. (1990). "Statistical Inference in Instrumental Variables Regression with I(1) Processes." Review of Economic Studies 57, pp. 99-125. 
Rawski, T. and Perkins, D.H. (2008). "Forecasting China's Economic Growth to 2025," Brandt, L. and Rawski, T. G. (Ed), In: China `s Great Economic Transformation. Cambridge: Cambridge University Press, 829-886.

Romer, P.M. (1990). "Endogenous Technological Change." Journal of Political Economy 98, pp. S71-102.

Segerstrom, P.S.; Anant, T.C.A. and Dinopoulos, E. (1990). "A Schumpeterian Model of the Product Life Cycle." American Economic Review 80, pp. 1077-1091.

Sinton, J.E. and Fridley, D.G. (2000). "What Goes Up: Recent Trends in China's Energy Consumption." Energy Policy 28, pp. 671-687.

Stock, J.H. and Watson, M.W. (1993). "A Simple Estimator of Cointegrating Vectors in Higher Order Integrated Systems." Econometrica 61, pp. 783-820.

The-World-Bank (2007). Cost of Pollution in China: Economic Estimates of Physical Damages. Beijing: The World Bank

Wagner, M. (2008). "The Carbon Kuznets Curve: A Cloudy Picture Emitted by Bad Econometrics?" Resource and Energy Economics 30, pp. 388-408.

Wang, Y. and Yao, Y. (2003). "Sources of China's Economic Growth 1952-1999: Incorporating Human Capital Accumulation." China Economic Review 14, pp. 32-52.

Zachariadis, M. (2003). "R\&D, Innovation, and Technological Progress: A Test of the Schumpeterian Framework without Scale Effects." Canadian Journal of Economics 36, pp. 566586. 